\title{
Recombinant human epoetin beta in the treatment of chemotherapy-related anemia
}

\author{
lain RJ Macpherson \\ Colin R Lindsay \\ Nicholas S Reed \\ Beatson West of Scotland Cancer \\ Centre, Glasgow, United Kingdom
}

Correspondence: lain RJ Macpherson Department of Medical Oncology, Beatson West of Scotland Cancer Centre, 1053 Great Western Road, Glasgow, GI 2 OYN, United Kingdom

$\mathrm{Tel}+44$ I4I 30I 7 I55

Fax +44 I4I 30। 7|24

Email iain.macpherson@ggc.scot.nhs.uk

\begin{abstract}
Anemia is a common complication of systemic anti-cancer treatment. In this context epoetin beta, like other erythropoiesis-stimulating agents (ESAs), has demonstrable efficacy in raising $\mathrm{Hb}$ concentration and reducing the requirement for red cell transfusion. Consequently ESA therapy has gained increasing prominence in the management of chemotherapy-related anemia. However, recent trial data have suggested a higher rate of thromboembolic events, enhanced tumor progression and reduced survival in some patients with cancer who receive ESA therapy. In response, regulatory authorities have mandated increasingly restrictive label changes. In light of these new developments we consider the current role of epoetin beta in the management of chemotherapy-related anemia.
\end{abstract}

Keywords: anemia, cancer, erythropoietin, epoetin, chemotherapy

\section{Introduction}

Anemia, defined as a hemoglobin $(\mathrm{Hb})$ concentration below the lower limit of normal, is common in patients with cancer and may be either disease or treatment-related. The World Health Organization (WHO), National Cancer Institute (NCI), and the Eastern Co-operative Oncology Group (ECOG) differ slightly in their classification of mild to moderate anemia although there is concordance on the definition of severe anemia as a $\mathrm{Hb}$ level $\leq 8.0 \mathrm{~g} / \mathrm{dL}$ (Table 1$)$.

There are many potential causes of anemia in a patient with cancer. ${ }^{1}$ Commonly cancer-related anemia can be attributed to the syndrome of anemia of chronic disease (ACD) which is mediated by pro-inflammatory cytokines and characterized by impaired iron utilization, reduced erythropoietin (EPO) mRNA synthesis and reduced RBC lifespan. ${ }^{2}$ This diagnosis requires exclusion of other possible causes, such as occult bleeding, iron or vitamin deficiency, autoimmune hemolysis or marrow infiltration. Alternatively anemia may be caused by cancer treatment itself. For example, severe or life-threatening anemia occurs in up to $40 \%$ of patients receiving platinum-based chemotherapy for lung cancer. ${ }^{3}$ Chemotherapy-related anemia primarily reflects cytotoxicity to erythroid precursors in the marrow although for certain agents such as platinums, toxicity to erythropoietin producing cells in the kidney is also relevant. Chemotherapy-related anemia is cumulative with increasing incidence over successive courses of treatment. For example, in an audit of patients receiving chemotherapy for solid tumors at 28 centers in the United Kingdom anemia (in this case defined as $\mathrm{Hb}<11 \mathrm{~g} / \mathrm{dL}$ ) was present in $17 \%$ of patients prior to the first cycle, rising to $38 \%$ by the sixth. ${ }^{4}$

\section{Incidence of anemia in cancer}

Several long-standing difficulties hindered attempts to define the true incidence of anemia in patients with cancer; for example, the lack of standardized toxicity criteria and the under-reporting of mild to moderate anemia due to a perceived lack of clinical 
importance as well as a lack of treatment options. ${ }^{3}$ It is only in the last 10 years that efforts such as the European Cancer Anemia Survey (ECAS) have significantly advanced our understanding of anemia related to cancer and its treatment. ${ }^{5}$ ECAS prospectively evaluated the prevalence and incidence of anemia (defined as $\mathrm{Hb}<12 \mathrm{~g} / \mathrm{dL}$ ) in over 15,000 cancer patients from 748 European cancer treatment centers. Overall $67.9 \%$ of patients were found to be anemic at least once during the study. In patients with normal $\mathrm{Hb}$ at enrolment the incidence of anemia was $53.7 \%$ overall, and was $62.7 \%$ in those patients who received chemotherapy. Of interest was the possible under-treatment of anemia identified by ECAS. For example, $61.1 \%$ of patients who were ever anemic did not receive treatment for anemia. Of these $47.2 \%$ had $\mathrm{Hb}$ levels of $10-11.9 \mathrm{~g} / \mathrm{dL}$ but $12.9 \%$ had a Hb between 8.0 and $9.9 \mathrm{~g} / \mathrm{dL}$ with $0.9 \%$ having $\mathrm{Hb}<8.0 \mathrm{~g} / \mathrm{dL}$. Furthermore, over half of anemic patients with WHO performance score $\geq 2$ did not receive treatment for their anemia.

ECAS also defined the marked variation in both the prevalence and treatment of anemia across different cancer types. Unsurprisingly hematological malignancies produced the highest incidences of anemia at $52 \%$ to $53 \%$ for lymphoma, myeloma, and leukemia. Of the solid tumors, anemia was most common in gynecological (49\%) and lung cancers (38\%). This may reflect the higher use of platinum containing regimes in ovarian and lung cancers. As many as $73.8 \%$ of breast cancer patients were not given treatment following an episode of anemia, with leukemic patients as the only cancer group who received treatment for anemia over $50 \%$ of the time.

\section{Symptoms of anemia and impact on quality of life (QoL)}

The most common symptom attributed to anemia is fatigue. Other symptoms and signs include dyspnoea, palpitations, headache, dizziness, chest pain, depression and tachycardia. Furthermore, chronic anemia may cause end-organ damage,

Table I Grading systems used in cancer-related anemia

\begin{tabular}{llll}
\hline \multirow{2}{*}{ Grade } & \multicolumn{3}{c}{ Hb level $(\mathbf{g} / \mathbf{d L})$} \\
\cline { 2 - 4 } & NCI & WHO & ECOG \\
\hline 0 & Normal limits & $\geq 11.0$ & Normal limits \\
2 & 10.0 to normal & $9.5-10.9$ & 10.0 to normal \\
3 & $8.0-10.0$ & $8.0-9.4$ & $8.0-10.0$ \\
4 & $6.5-7.9$ & $6.5-7.9$ & $6.5-7.9$ \\
\hline
\end{tabular}

Abbreviations: $\mathrm{NCl}$, National Cancer Institute; WHO, World Health Organization; ECOG, Eastern Co-operative Oncology Group. affecting particularly the cardiovascular system, lungs, kidneys, and central nervous system. ${ }^{6}$ Anemia may be particularly debilitating in cancer patients with existing co-morbidities such as chronic obstructive pulmonary disease or ischemic heart disease. ${ }^{7}$ Many of the symptoms of anemia are non-specific and, in some patients, will be attributable to the underlying malignancy itself rather than reflecting the presence of anemia. Despite this a significant correlation between $\mathrm{Hb}$ concentration and QoL has been demonstrated in patients with cancer, although factors other than anemia such as pain and sleep disturbance are also of importance. ${ }^{8,9}$

\section{Relationship of anemia to cancer outcomes}

Anemia is well recognized as an independent adverse prognostic factor in various cancers. These include head and neck, lung, prostate, cervical and hematological malignancies. ${ }^{10}$ Similarly, intra-tumoral hypoxia has also been linked to poor outcome, although it should be acknowledged that the relationship between anemia and intra-tumoral hypoxia is complex. ${ }^{11}$ These observations have led to the hypothesis that correction of anemia may have the potential not only to improve QoL but also to improve response to anticancer therapy and survival. Nonetheless, despite the biological plausibility of a causal link between anemia/intra-tumoral hypoxia and poor outcome the existence of such a relationship remains unproven. In particular, whether situations exist where anti-cancer therapy may be potentiated by the correction of anemia remains contentious. A provocative retrospective analysis of 494 patients who received chemo-radiotherapy for cervical cancer in two GOG trials suggested that on-treatment, but not baseline, Hb concentration was predictive of disease progression thus generating the hypothesis that there may be an interaction between anemia and treatment efficacy in this setting. ${ }^{12}$ Another retrospective analysis, conducted by Grogan and colleagues, suggested that correction of anemia by RBC transfusion might overcome the negative prognostic effects of low $\mathrm{Hb}$ in patients receiving radiotherapy for cervical carcinoma. ${ }^{13}$ This strategy has not been tested prospectively although, as discussed below, a prospective study evaluating recombinant erythropoietin (hereafter referred to as epoetin) beta in a related context failed to demonstrate improved tumor control or survival despite effectively raising $\mathrm{Hb} .{ }^{14}$ Likewise, retrospective data which suggested improved tumor control and survival for correction of anemia in patients receiving neoadjuvant chemo-radiotherapy for locally advanced head and neck cancer have yet to be confirmed prospectively. ${ }^{15}$ 
Accordingly, whilst the goal of enhanced treatment efficacy by correction of anemia remains attractive, proof of principle for this approach is outstanding.

\section{Treatment of anemia in cancer}

RBC transfusions have historically been the standard treatment for cancer- and cancer treatment-related anemia and offer a rapid and effective therapeutic intervention. Since the 1990s several erythropoiesis stimulating agents (ESAs) including epoetin beta have been approved for the treatment of chemotherapy-related anemia. However, given that the median time to response for ESAs is measured in weeks $\mathrm{RBC}$ transfusion has remained the treatment of choice for severe anemia. RBC transfusion is associated with several potentially life-threatening hazards all of which have a low and well quantified level of risk. ${ }^{16}$ These include transmission of bacterial or viral infection, transfusion related reactions and iron overload. A further consideration is the finite supply of donor blood and the need to conserve this scare resource.

\section{Epoetin beta}

\section{Physiology of human erythropoietin}

Human EPO is an acidic glycoprotein hormone, predominantly produced in the kidney and, to a lesser extent, the liver. ${ }^{17,18}$ Intracellular hypoxia causes increased transcription of EPO in a HIF-2 $\alpha$-dependent manner. ${ }^{19}$ Subsequent binding of EPO to its receptor on erythroid progenitor cells activates anti-apoptotic pathways resulting in a net increase in RBC production. ${ }^{20}$ In addition, the EPO receptor (EPO-R) is also known to be expressed by many non-erythroid cell lineages. In-keeping with this observation EPO has recently emerged as an important regulator of development, angiogenesis and wound healing as well as having important neuro-protectant and cardiovascular-protectant properties. ${ }^{21}$

\section{Epoetin beta}

Epoetin beta (NeoRecormon ${ }^{\circledR}$; F. Hoffmann-La Roche Ltd, Basel, Switzerland) is a glycoprotein manufactured by recombinant DNA technology to have an amino acid and carbohydrate composition indistinguishable from human EPO. ${ }^{22}$ It is approved within the European Union for the treatment of symptomatic anemia in adult patients with non-myeloid malignancies receiving chemotherapy. Other licensed indications include the treatment of symptomatic anemia associated with chronic renal failure in adult and pediatric patients, increasing the yield of autologous blood from patients in a pre-donation programme, and in prevention of the anemia of prematurity.

\section{Pharmacokinetics and dosing of epoetin beta}

Epoetin beta, when administered by subcutaneous injection, has a bioavailability of $23 \%$ to $42 \%$. Maximum serum concentration is reached after an average of 12 to 28 hours, with a terminal half-life of 13 to 28 hours. ${ }^{22}$ Previously epoetin beta was administered by subcutaneous injection threetimes-weekly to achieve a total weekly dose of 30,000 IU (approximately $450 \mathrm{IU} / \mathrm{kg}$ ), a regimen developed within the context of renal dialysis. This has largely been superseded by a more convenient once-weekly dosing regimen for which similar efficacy to 3-times-weekly dosing has been demonstrated in patients with both hematological and solid tumors. ${ }^{23,24}$ Dose modification may be required depending on hematological response as per the product label. ${ }^{22}$ The aim should be to use the lowest possible dose of epoetin to gradually increase the $\mathrm{Hb}$ concentration to avoid the need for transfusion. ${ }^{25}$

\section{Efficacy of epoetin beta}

The efficacy of ESA therapy can be evaluated in several ways. The simplest and most direct measure is to demonstrate a rise in $\mathrm{Hb}$ levels. In this regard clinical trials have often utilized "Hb response", defined as an increase in $\mathrm{Hb}$ concentration of at least $2 \mathrm{~g} / \mathrm{dL}$ as an endpoint. However, more meaningful clinical endpoints include reduced transfusion requirement and improved quality of life. A series of systematic reviews and meta-analysis have considered the efficacy of ESA therapy, generally without discriminating between particular agents within this class. Although there are no published data regarding the comparative efficacy of epoetin-beta with epoetin-alfa or darbepoetin these agents are considered by regulatory agencies and professional bodies as belonging to a single class without significant difference in pharmacodynamics, clinical indications for use, efficacy or toxicity when used at recommended doses. ${ }^{26}$

\section{Efficacy: hematological responses and transfusion requirements}

The efficacy of epoetin beta in achieving hematological response and reducing transfusion requirements in patients receiving cancer treatment has been well defined in several randomized studies ${ }^{14,27-34}$ and meta-analyses. ${ }^{35-38}$ An example is the recently reported BRAVE trial which randomly assigned 463 woman receiving chemotherapy for metastatic breast cancer to epoetin-beta or supportive care. ${ }^{34}$ The mean increase in $\mathrm{Hb}$ from baseline was $1.3 \mathrm{~g} / \mathrm{dL}$ in the epoetin group with a decrease of $0.4 \mathrm{~g} / \mathrm{dL}$ in the control group. Epoetin therapy was 
associated with a significant reduction in blood transfusion from $27 \%$ of patients in the control arm to $14 \%$ in the epoetin $\operatorname{arm}(\mathrm{p}<0.001)$. For the subgroup of patients with baseline $\mathrm{Hb}$ less that $11 \mathrm{~g} / \mathrm{dL}, 45.9 \%$ of patients in the control arm required transfusion versus $29 \%$ in the epoetin arm. Similarly, Strauss et al randomized 74 patients receiving radio-chemotherapy for cervical cancer to epoetin-beta or supportive care. ${ }^{14}$ By week 4 the median $\mathrm{Hb}$ had increased by $1.1 \mathrm{~g} / \mathrm{dL}$ in the epoetin group but fallen by $0.6 \mathrm{~g} / \mathrm{dL}$ in the control group. In both of these trials the improvements in $\mathrm{Hb}$ were shown to be maintained throughout the treatment period.

Boogaerts and colleagues conducted a meta-analysis of three trials in which patients undergoing chemotherapy for solid tumors received epoetin-beta. ${ }^{39}$ The median increase in $\mathrm{Hb}$ level at 16 weeks was $1.5 \mathrm{~g} / \mathrm{dL}$ in the treatment group with no change in the control group. This was associated with a $53 \%$ reduction in the risk of receiving a transfusion. The magnitude of $\mathrm{Hb}$ rise was similar whether patients received platinum or non-platinum based chemotherapy. The benefits of epoetin in raising $\mathrm{Hb}$ and reducing risk of transfusion were seen as early as 4 weeks.

A recent Health Technology Assessment commissioned by the United Kingdom National Institute for Health Research (which itself updated an earlier Cochrane review ${ }^{35}$ ) considered 46 RCTs containing 7304 patients comparing ESAs plus supportive care versus supportive care alone. ${ }^{38}$ The majority of trials utilized ESAs in conjunction with anti-cancer therapy although 4 trials included patients receiving no anti-cancer therapy. Ten of the 46 trials related specifically to epoetin-beta. In this meta-analysis 53\% of patients receiving ESAs achieved a hematological response compared with $15.7 \%$ of control patients. Overall the pooled relative risk for hematological response was 3.40 (95\% CI, 3.01-3.83) in favor of ESAs whilst the mean difference in overall change in $\mathrm{Hb}$ concentrations between intervention and control arms was $1.63 \mathrm{~g} / \mathrm{dL}$ (95\% CI, 1.46-1.8) in favor of ESAs. The relative risk for receiving blood transfusion was 0.63 (95\% CI, 0.58-0.67) in favor of ESAs with transfusion occurring in $30.6 \%$ of patients receiving ESAs compared to $48.7 \%$ of control patients. ESA use was associated with a mean difference of 1.05 units of blood transfused.

Taken together these data clearly indicate that ESAs as a class, and epoetin beta specifically, are effective at achieving hematological response in more than $50 \%$ of patients and allow for a modest but significant reduction in blood transfusion.

\section{Efficacy: quality of life}

Studies of epoetin beta and other ESAs have utilized a variety of validated tools to assess QoL. These include FACT
(Functional Assessment of Cancer Treatment) questionnaires incorporating additional questions relating to fatigue (FACT-F) or anemia (FACT-An), visual analogue scales and other questionnaires such as SF-36. ${ }^{35}$ Although interesting, initial reports of improved QoL were based on open label single arm studies and thus comprised only low level evidence. ${ }^{40,41}$ However, subsequent double-blind randomized placebo-controlled studies have confirmed improvements in QoL with ESA therapy (summarized by Wilson and colleagues ${ }^{38}$ ). For example, Osterborg and colleagues reported statistically significant increases in FACT-An and FACT-G scales in transfusiondependent patients with lymphoproliferative malignancy after 12 and 16 weeks of treatment with epoetin beta compared to those patients who received placebo. ${ }^{30}$ The improvement in QoL correlated with the increase in $\mathrm{Hb}$ concentration. These data are inkeeping with another randomized double-blind placebo-controlled trial in which 375 anemic patients receiving chemotherapy were randomized to epoetin-alfa or placebo. ${ }^{42}$ Again there was a significant increase in QoL scores in the treatment arm with a strong correlation between change in $\mathrm{Hb}$ concentration and change in QoL. Despite such results in individual trials, concerns with the validity of QoL data in many studies together with the diversity in QoL scales used has led several groups to conclude that meaningful quantitative meta-analysis is not possible. ${ }^{36,43}$ Allowing for this the recent HTA systematic review utilized a qualitative vote counting approach to conclude that available data indicated a positive effect for ESA therapy on QoL, albeit the magnitude of this effect was poorly defined. ${ }^{38}$

\section{Safety and tolerability}

The safety profile of ESAs remains a highly contentious issue. ${ }^{44,45}$ In the presence of accumulating data indicating potential harm, regulatory authorities have increasingly restricted approved indications for ESA use. These concerns relate primarily to thromboembolic events (TEEs), possible enhanced tumor progression, and reduced overall survival. Other toxicities of epoetin beta include hypertension, headache and, rarely, pure red cell aplasia. Treatment-related flu-like symptoms are uncommon and usually transient. ${ }^{22}$

\section{Thromboembolic events}

A recent meta-analysis evaluated the incidence of venous thromboembolism in 38 trials of ESAs including 8172 patients. The risk of venous thromboembolism was significantly increased in patients receiving ESAs compared to control (RR 1.57; 95\% CI 1.31-1.87). ${ }^{46}$ Similarly, a meta-analysis restricted to 12 trials of epoetin beta confirmed that TEEs 
were more common in patients receiving epoetin $(0.22$ events per patient-year) compared with control ( 0.14 events per patient-year). ${ }^{47}$ The enhanced risk of TEEs in patients with cancer- or cancer treatment-related anemia is consistent with the risk seen in other ESA indications including chronic renal failure $^{48,49}$ and when used perioperatively. ${ }^{50}$

Specific risk factors for TEEs have not been defined. In particular, a conclusive relationship between TEE and either $\mathrm{Hb}$ level achieved or rate of $\mathrm{Hb}$ rise has not been definitively demonstrated in patients with cancer. ${ }^{37}$ The 2006 Agency for Healthcare Research and Quality meta-analysis identified a trend for increasing risk with increased target $\mathrm{Hb} .{ }^{36}$ However, the authors cautioned that TEE rates may have been underreported in many trials and that, crucially, individual patient data on $\mathrm{Hb}$ concentration preceding a TEE was not available. Glaspy and colleagues have started to address this with an analysis of individual patient-level data for 901 patients enrolled in 6 RCTs of darbepoetin to treat chemotherapy-induced anemia. ${ }^{51}$ In this exploratory analysis they examined the relationship of both achieved $\mathrm{Hb}$ level and rate of $\mathrm{Hb}$ increase to TEE. Achieving a $\mathrm{Hb}$ level $>12 \mathrm{~g} / \mathrm{dL}$ or an increase in $\mathrm{Hb}>1 \mathrm{~g} / \mathrm{dL}$ in 14 days was associated with an increased risk of TEEs. It is hoped that an updated Cochrane analysis utilizing individual patient data will provide more definitive evidence on this point. At present both ASCO/ASH and ESMO guidelines recommend that each patient's baseline thromboembolic risk is taken into account when considering the risk: benefit ratio for commencing ESA therapy. ${ }^{25,26}$ Whether anti-platelet or anticoagulant therapy may have a role in modulating the risk of TEE is unknown. ${ }^{52}$

\section{Overall survival/tumor progression}

Significant concerns regarding a possible negative impact of ESA therapy on cancer patient outcomes first arose in 2003 with the publication of 2 randomized controlled trials demonstrating increased mortality in patients receiving epoetin beta (ENHANCE) $)^{31}$ or epoetin alfa (BEST), ${ }^{53}$ respectively. In contrast to earlier studies both of these trials prospectively evaluated survival (progression free or overall) as a primary endpoint.

In the ENHANCE trial Henke and colleagues randomized patients with head and neck cancer undergoing radiotherapy to epoetin beta or placebo. Mean $\mathrm{Hb}$ concentration in the treatment arm was $11.7 \mathrm{~g} / \mathrm{dL}$ at baseline rising to $14.8 \mathrm{~g} / \mathrm{dL}$ at 4 weeks and $15.4 \mathrm{~g} / \mathrm{dL}$ at 9 weeks. Both locoregional progression (RR 1.69; 95\% CI 1.16-2.47) and death (RR 1.39; 95\% CI 1.05-1.84) were more likely in the treatment arm. The BEST trial randomized patients who were receiving first-line chemotherapy for metastatic breast cancer to epoetin alfa or placebo with the aim of maintaining $\mathrm{Hb}$ in the range 12 to $14 \mathrm{~g} / \mathrm{dL}$. Treatment was initiated if baseline or on-treatment $\mathrm{Hb}$ was $\leq 13 \mathrm{~g} / \mathrm{dL}$. This trial was terminated early after an interim analysis revealed an excess in 12 month mortality (the primary endpoint) in patients receiving epoetin $(76 \%$ versus $70 \%$ in control arm, $\mathrm{p}=0.0117)$. Whilst the designs of both of these trials have been heavily criticized, ${ }^{53-56}$ their findings were sufficient to prompt an FDA Oncologic Drug Advisory Committee (ODAC) to recommend that further studies be performed to identify risks associated with ESAs. Specifically these studies were to be double-blind placebo-controlled trials recruiting patients with homogenous tumor types and with survival as primary endpoint. It was also recommended that incidence of TEEs be incorporated as a prospectively defined endpoint. Since 2004 accruing data has prompted two further ODAC meetings, in May 2007 and March 2008. In addition to the BEST and ENHANCE trials, the March 2008 ODAC considered data from a further 6 studies. ${ }^{57}$ Four of these showed statistically significant tumor progression and/or reduced survival and a further 2 studies demonstrated a non-significant trend towards tumor progression and/or reduced survival. Of the 8 studies considered, 4 utilized ESAs in patients receiving chemotherapy, 2 in conjunction with radiotherapy, and 2 in the absence of anti-cancer therapy.

The 20000161 trial randomized patients with lymphoid malignancies undergoing chemotherapy to receive darbepoetin or placebo. ${ }^{58}$ The primary endpoint was $\mathrm{Hb}$ response. The target $\mathrm{Hb}$ was 13 to $14 \mathrm{~g} / \mathrm{dL}$ for woman and 13 to $15 \mathrm{~g} / \mathrm{dL}$ for men. Six percent of patients on the darbepoetin arm died during or within 30 days of treatment versus $2 \%$ in the control arm. The hazard ratio (HR) for death was $1.37(\mathrm{p}=0.04) .{ }^{46}$ Most deaths were attributed to progressive disease.

The PREPARE trial randomized 733 patients with early breast cancer in a $2 \times 2$ factorial design to standard or dose dense/ dose intense chemotherapy and to darbepoetin or transfusion support with a target $\mathrm{Hb}$ of 12.5 to $13 \mathrm{~g} / \mathrm{dL} .{ }^{59}$ Comparison of relapse-free and overall survival of the ESA versus transfusion support arms was a secondary endpoint. Three-year relapsefree and overall survival were lower in patients receiving darbepoetin with HRs of 1.42 (95\% CI 0.93-2.18) and 1.33 (95\% CI 0.99-1.79) in favor of transfusion respectively.

The GOG-191 trial randomized 114 patients with stage $2 \mathrm{~B}$ to $4 \mathrm{~A}$ cervical cancer who were receiving concurrent cisplatin and radiotherapy to either epoetin alfa or transfusion support. ${ }^{60}$ The target $\mathrm{Hb}$ was $12-14 \mathrm{~g} / \mathrm{dL}$. The primary endpoint was progression-free survival. The trial was terminated early due to an increase in TEEs. Subsequently, 
3 year progression-free and overall survival were found to be higher in the transfusion group with HR of 1.06 (95\% CI 0.58-1.91) and 1.28 (95\% CI 0.68-2.42).

The DAHANCA 10 trial randomized 522 patients with baseline $\mathrm{Hb}<14 \mathrm{~g} / \mathrm{dL}$ who were undergoing radical radiotherapy for head and neck cancer to receive darbepoetin alfa. ${ }^{61}$ The primary outcome was locoregional disease control. The trial was terminated after planned interim analysis demonstrated significantly reduced locoregional control (5-year actuarial loco-regional control $56 \%$ vs $69 \%$ [p $=0.02$, RR: $1.44,95 \%$ CI 1.06-1.96]) and disease-free survival ( $48 \%$ vs $63 \%$ for darbepoetin vs control, $p=0.004$, RR: 1.49 [1.13-1.97]). A trend towards reduced overall survival was seen ( $38 \%$ vs $51 \%$ for darbepoetin and control respectively, $\mathrm{p}=0.08$, RR: 1.28 [0.98-1.68]).

Finally, 2 double blind RCTs studied ESAs for cancerrelated anemia in the absence of anti-cancer therapy. In EPO-CAN-20 patients with metastatic NSCLC and $\mathrm{Hb}<12.1 \mathrm{~g} / \mathrm{dL}$ were randomized to epoetin alfa vs placebo with a target $\mathrm{Hb}$ of 12 to $14 \mathrm{~g} / \mathrm{dL} .^{62}$ Primary endpoint was quality of life. An unplanned safety analysis undertaken after accrual of 70 patients revealed a significant reduction in median survival in the epoetin arm (63 vs 129 days; HR, 1.84; $\mathrm{p}=0.04$ ), leading to termination of the trial. The 20010103 trial randomized 989 patients with a variety of tumor types and $\mathrm{Hb} \leq 11 \mathrm{~g} / \mathrm{dL}$ to darbepoetin or placebo. ${ }^{63}$ Target $\mathrm{Hb}$ concentration was 12 to $13 \mathrm{~g} / \mathrm{dL}$ and the primary endpoint was the incidence of blood transfusion. There was a significant difference in survival between the two groups in favor of placebo (HR $=1.22 ; 95 \% \mathrm{CI}, 1.03-1.45 ; \mathrm{p}=0.022$ ).

In contrast other randomized trials have not reported excess mortality in patients receiving ESAs ${ }^{38}$ For example, the BRAVE trial randomized 463 women with metastatic breast cancer and $\mathrm{Hb} \leq 12.9 \mathrm{~g} / \mathrm{dL}$ to receive epoetin beta or supportive care commencing simultaneously with anthracycline or taxane based chemotherapy. ${ }^{34}$ The target $\mathrm{Hb}$ concentration was 13 to $15 \mathrm{~g} / \mathrm{dL}$ and the primary endpoint was overall survival. Although patients receiving epoetin beta experienced more TEEs ( $13 \%$ vs $6 \%$, $\mathrm{p}=0.12)$ there were no significant differences in either survival or disease progression. Another study randomized 343 patients with lymphoproliferative malignancy who were transfusion dependent and who had a mean baseline $\mathrm{Hb}$ of $9.2 \mathrm{~g} / \mathrm{dL}$ to epoetin beta or placebo. ${ }^{64}$ With median follow-up of 27 months there was no significant difference in survival.

Aapro and colleagues recently conducted a meta-analysis using individual patient data for 2297 patients entered into 12 randomized controlled trials conducted in patients receiving epoetin beta in conjunction with chemotherapy, radiotherapy or surgery. ${ }^{47}$ Long term follow-up data was limited with follow-up further than 28 days after the end of the study period available for only 4 of the 12 trials. For all 12 trials there was no significant difference in overall survival between the epoetin and control arms. However, an analysis including only the 4 trials with long term follow-up demonstrated a trend to poorer survival in the epoetin arm (HR 1.13, 95\% CI 0.98-1.31, p = 0.082). Similar results were obtained for disease progression with no difference between epoetin and control arms in the analysis of all 12 studies but a trend towards increased disease progression in 3 trials for which long term follow-up data was available (HR 1.13, 95\% CI 0.95-1.34, $\mathrm{p}=0.165$ ). In a pre-planned subgroup analysis of patients with baseline $\mathrm{Hb} \leq 11 \mathrm{~g} / \mathrm{dL}$ ( $n=1246)$ no difference in survival was demonstrated. Interestingly, patients with baseline $\mathrm{Hb} \leq 11 \mathrm{~g} / \mathrm{dL}$ demonstrated a reduced risk of progression in the pooled analysis of 12 studies (HR $0.8,95 \%$ CI $0.65-0.99, p=0.041$ ) and a trend towards reduced risk of progression in the 3 trials for which longer term data were available $(\mathrm{HR}=0.85,95 \% \mathrm{CI}$ $0.64-1.13, p=0.267$ ). Importantly, however, the largest and most recent meta-analysis of ESA therapy which included 13,611 patients treated in 51 phase 3 trials (epoetin alfa or beta in 40 trials, darbepoetin in 11 trials) has identified significantly higher mortality in patients treated with ESAs versus control (HR 1.10; 95\% CI 1.01-1.20; $\mathrm{p}=0.03$ ). ${ }^{46}$

The cause of increased mortality in patients with cancer exposed to ESA therapy is not clear but cannot be entirely attributed to increased TEEs. The identification of EPO receptors on tumor cells taken together with observations of enhanced tumor progression raises the possibility that epoetins may directly stimulate tumor proliferation or survival. Preclinical data (recently reviewed by Arcasoy ${ }^{65}$ ) have demonstrated EPO-induced stimulation of proliferation, invasion and survival in a variety of cancer cell lines in vitro. However, preclinical models have so far failed to provide in vivo evidence for a detrimental effect of exogenous EPO on syngeneic or xenograft tumor progression. An apparent link between EPO-R expression on tumor cells and poor outcome in patients receiving epoetin beta within the ENHANCE trial has been strongly challenged, ${ }^{66-70}$ primarily due to concerns relating to the specificity of the EPO-R antibody but also because of imbalances in baseline characteristics which may have been further compounded by the availability of tissue for only a minority of the study population. Even so this intriguing finding clearly demands 
further study as more robust tools with which to analyze EPO-R expression become available. The role of EPO-R signaling in host cells is also of interest with compelling in vivo data supporting a role for EPO-R signaling in tumor neovascularization. ${ }^{71,72}$

In considering the risk: benefit ratio for epoetin beta therapy it is important to recognize that none of the 8 trials considered by the March 2008 ODAC evaluated ESAs within their licensed indications; specifically excessively high $\mathrm{Hb}$ concentrations were targeted and/or ESAs were used in patients not receiving chemotherapy. Whether ESA therapy used within currently approved indications might avoid these negative effects remains a critically important but unanswered question. Certainly target $\mathrm{Hb}$ concentration does appear to be an important factor in the context of chronic renal failure where ESA therapy targeting a higher rather than lower $\mathrm{Hb}$ concentration has been associated with increased cardiovascular events and mortality. ${ }^{48,49}$ Nonetheless, the FDA view is that "There are no studies which clearly establish the effect of ESAs on survival or on tumor promotion when ESAs were administered in accordance with recommended dose in product labeling across multiple cancer subtypes" and the black box warning approved by the FDA in November 2007 stated "the risks of decreased survival and tumor progression have not been excluded when ESAs are dosed to target $\mathrm{Hb}<12 \mathrm{~g} / \mathrm{dL}$ ". Paradoxically, an exploratory FDA analysis of the 20000161 and 20010103 trials demonstrated that despite high target $\mathrm{Hb}$ levels the median $\mathrm{Hb}$ levels actually achieved were $<12 \mathrm{~g} / \mathrm{dL}$. In the 20000161 trial the median achieved $\mathrm{Hb}$ was $11.0 \mathrm{~g} / \mathrm{dL}$ (interquartile range 9.8 to 12.1 ) whilst in the 20010103 trial median achieved $\mathrm{Hb}$ was $10.6 \mathrm{~g} / \mathrm{dL}$ (interquartile range 9.4-11.8). The poorer survival observed in these two trials, in which the majority of patients did not have excessive $\mathrm{Hb}$ concentration, at least generates a hypothesis that there may not be a lower threshold below which ESAs are safe. These safety signals have prompted recent label changes by FDA and EMEA as discussed below. Although epoetin beta is not marketed in the USA and not under FDA jurisdiction their conclusions on ESA therapy are relevant nevertheless.

\section{Pure red cell aplasia (PRCA)}

PRCA is a rare complication of ESA therapy resulting from the production of anti-epoetin antibodies and characterized by sudden loss of response to ESA, severe anemia and low reticulocyte count. PRCA has been primarily associated with the use of a specific epoetin alfa preparation (Eprex ${ }^{\circledR}$, Janssen-Cilag Ltd, Bucks, UK) in patients receiving hemodialysis. ${ }^{73}$

\section{Current role of epoetin beta in chemotherapy-related anemia}

Together with other ESAs, the role of epoetin beta in the treatment of chemotherapy-related anemia continues to evolve. Recently both the EMEA and the FDA have restricted the indications for ESAs based on concerns of enhanced tumor progression and decreased survival as discussed above. In July 2008 the FDA required the makers of ESAs available in the USA to update their labels to state, "ESAs are not indicated for patients receiving myelosuppressive therapy when the anticipated outcome is cure". ${ }^{74}$ Similarly, in June 2008 the Committee for Medicinal Products for Human Use of the EMEA agreed that product labels for ESAs including epoetin beta should be updated to include a warning that "transfusion should be the preferred method for correcting anemia in cancer patients, especially those with a long life expectancy". ${ }^{75}$ This follows earlier guidance issued in October 2007 that epoetins should be used in the treatment of anemia only if associated with symptoms and stipulating a target $\mathrm{Hb}$ concentration for all epoetins of $10 \mathrm{~g} / \mathrm{dL}$ to $12 \mathrm{~g} / \mathrm{dL}$ with a warning not to exceed a concentration of $12 \mathrm{~g} / \mathrm{dL}{ }^{76} \mathrm{It}$ should be noted that these ESA label changes post-date the most recent $\mathrm{ASCO} / \mathrm{ASH}^{26}{ }^{26} \mathrm{ESMO}^{25}$ and $\mathrm{EORTC}^{77}$ published guidelines but are reflected in updated NCCN guidelines. ${ }^{78}$ Taking recent label changes into consideration the following recommendations can be made for the use of epoetin beta:

- Epoetin beta may be indicated in the treatment of symptomatic anemia $(\mathrm{Hb} \leq 11 \mathrm{~g} / \mathrm{dL})$ in patients undergoing palliative chemotherapy. In this context the therapeutic goal is to reduce the need for blood transfusion.

- Epoetin beta should not be used prophylactically to prevent anemia nor is epoetin beta approved for cancer-associated anemia in patients not receiving chemotherapy.

- Where chemotherapy is given with curative intent the risk:benefit ratio of epoetin therapy may be unfavorable and transfusion should be preferred.

- In all settings the risk:benefit ratio of transfusion versus epoetin therapy should be discussed with the patient.

- Patients should be iron replete and intravenous iron supplementation may be associated with enhanced response to ESA therapy.

- Epoetin beta dose should be titrated to the minimum which avoids need for transfusion as per the product label. 
- Epoetin beta should be discontinued when $\mathrm{Hb}$ is $>12 \mathrm{~g} / \mathrm{dL}$.

- Epoetin beta should be discontinued within 4 weeks of completing the course of chemotherapy.

The cost of epoetin beta is also highly pertinent and local health economic assessment provides a further determinant of its use. For example, in a United Kingdom context the National Institute for Health and Clinical Excellence (NICE) estimated ESA therapy in most clinical settings to be associated with an prohibitively high incremental cost effectiveness ratio of between $£ 30,000$ to $£ 53,000$ (US $\$ 55,000$ to 98,000) per additional quality adjusted life-year (QALY) gained. ${ }^{79}$

\section{Conclusions}

Epoetin beta has demonstrable efficacy in raising $\mathrm{Hb}$ concentration and reducing the need for transfusion in patients with chemotherapy-related anemia. Nonetheless, accumulating evidence of undesirable effects has led regulatory authorities to mandate increasing restrictions on the use of epoetin beta and other ESAs. Yet many fundamental questions relating to ESA therapy in chemotherapy-related anemia remain unanswered. These include:

- What is the risk:benefit ratio of ESA therapy when used to target $\mathrm{Hb}<12 \mathrm{~g} / \mathrm{dL}$ ? As alluded to above, the risk:benefit ratio of ESA therapy, when used to target lower $\mathrm{Hb}$ concentrations has not been defined in prospective clinical studies in either curative or palliative settings.

- Does tumor type influence the risk: benefit ratio of ESA therapy? For example, the poorer outcomes observed in patients with breast or head and neck cancer have not been replicated in patients with small cell lung cancer. ${ }^{80,81}$ Whether this truly indicates a role for disease type in determining outcomes with ESA therapy remains to be seen.

- Is tumor EPO-R expression predictive of harm in patients receiving ESAs? This will require development of a robust and widely accepted assay for determination of EPO-R expression by tumors together with further preclinical investigation of the consequences of EPO-R signaling in cancer and stromal cells. The role of the tumor micro-environment in modulating EPO-R signaling pathways must also be defined.

Although some of these points may be addressed preclinically and by individual patient level meta-analysis of existing data, there is also a need for further placebocontrolled randomized trials conducted in patients with homogenous malignancies and with survival and tumor response as endpoints. For now, the significant degree of uncertainty regarding the risk: benefit ratio of epoetin beta therapy justifies the precautionary approach adopted by regulatory agencies as the optimal means of preserving patient safety.

\section{Disclosures}

The authors have no conflicts of interest to disclose.

\section{References}

1. Moliterno AR, Spivak JL. Anemia of cancer. Hematol Oncol Clin North Am. 1996;10(2):345-363.

2. Weiss G, Goodnough LT. Anemia of chronic disease. $N$ Engl J Med. 2005;352(10):1011-1023.

3. Groopman JE, Itri LM. Chemotherapy-induced anemia in adults: incidence and treatment. J Natl Cancer Inst. 1999;91(19):1616-1634.

4. Barrett-Lee PJ, Bailey NP, O'Brien ME, Wager E. Large-scale UK audit of blood transfusion requirements and anaemia in patients receiving cytotoxic chemotherapy. Br J Cancer. 2000;82(1):93-97.

5. Ludwig H, Van Belle S, Barrett-Lee P, et al. The European Cancer Anaemia Survey (ECAS): a large, multinational, prospective survey defining the prevalence, incidence, and treatment of anaemia in cancer patients. Eur J Cancer. 2004;40(15):2293-2306.

6. Ludwig H, Strasser K. Symptomatology of anemia. Semin Oncol. 2001;28(2 Suppl 8):7-14.

7. Morere JF. Role of epoetin in the management of anaemia in patients with lung cancer. Lung Cancer. 2004;46(2):149-156.

8. Holzner B, Kemmler G, Greil R, et al. The impact of hemoglobin levels on fatigue and quality of life in cancer patients. Ann Oncol. 2002;13(6):965-973.

9. Lind M, Vernon C, Cruickshank D, et al. The level of haemoglobin in anaemic cancer patients correlates positively with quality of life. $\mathrm{Br} J$ Cancer. 2002;86(8):1243-1249.

10. Caro JJ, Salas M, Ward A, Goss G. Anemia as an independent prognostic factor for survival in patients with cancer: a systemic, quantitative review. Cancer. 2001;91(12):2214-2221.

11. De Los Santos JF, Thomas GM. Anemia correction in malignancy management: threat or opportunity? Gynecol Oncol. 2007;105(2):517-529.

12. Winter WE, 3rd, Maxwell GL, Tian C, et al. Association of hemoglobin level with survival in cervical carcinoma patients treated with concurrent cisplatin and radiotherapy: a Gynecologic Oncology Group Study. Gynecol Oncol. 2004;94(2):495-501.

13. Grogan M, Thomas GM, Melamed I, et al. The importance of hemoglobin levels during radiotherapy for carcinoma of the cervix. Cancer. 1999;86(8):1528-1536.

14. Strauss HG, Haensgen G, Dunst J, et al. Effects of anemia correction with epoetin beta in patients receiving radiochemotherapy for advanced cervical cancer. Int J Gynecol Cancer. 2008;18(3):515-524.

15. Glaser CM, Millesi W, Kornek GV, et al. Impact of hemoglobin level and use of recombinant erythropoietin on efficacy of preoperative chemoradiation therapy for squamous cell carcinoma of the oral cavity and oropharynx. Int J Radiat Oncol Biol Phys. 2001;50(3):705-715.

16. Kleinman S, Chan P, Robillard P. Risks associated with transfusion of cellular blood components in Canada. Transfus Med Rev. 2003;17(2):120-162.

17. Koury ST, Bondurant MC, Koury MJ. Localization of erythropoietin synthesizing cells in murine kidneys by in situ hybridization. Blood. 1988;71(2):524-527.

18. Koury ST, Bondurant MC, Koury MJ, Semenza GL. Localization of cells producing erythropoietin in murine liver by in situ hybridization. Blood. 1991;77(11):2497-2503.

19. Rankin EB, Biju MP, Liu Q, et al. Hypoxia-inducible factor-2 (HIF-2) regulates hepatic erythropoietin in vivo. J Clin Invest. 2007;117(4):1068-1077.

20. Koury MJ. Erythropoietin: the story of hypoxia and a finely regulated hematopoietic hormone. Exp Hematol. 2005;33(11):1263-1270. 
21. Arcasoy MO. The non-haematopoietic biological effects of erythropoietin. Br J Haematol. 2008;141(1):14-31.

22. Roche Products Limited. NeoRecormon Summary of Product Characteristics. Available at: http://www.emea.europa.eu/humandocs/PDFs/ EPAR/Neorecormon/H-116-PI-en.pdf. Accessed Sep 17th, 2008.

23. Cazzola M, Beguin Y, Kloczko J, Spicka I, Coiffier B. Once-weekly epoetin beta is highly effective in treating anaemic patients with lymphoproliferative malignancy and defective endogenous erythropoietin production. Br J Haematol. 2003;122(3):386-393.

24. Spaeth D. Epoetin beta once weekly: review of its efficacy and safety in patients with chemotherapy-induced anemia. Expert Rev Anticancer Ther. 2008;8(6):875-885.

25. Greil R, Thodtman R, Roila F. Erythropoietins in cancer patients: ESMO recommendations for use. Ann Oncol. 2008;19 Suppl 2:ii113-115.

26. Rizzo JD, Somerfield MR, Hagerty KL, et al. Use of epoetin and darbepoetin in patients with cancer: 2007 American Society of Clinical Oncology/American Society of Hematology clinical practice guideline update. J Clin Oncol. 2008;26(1):132-149.

27. ten Bokkel Huinink WW, de Swart CA, van Toorn DW, et al. Controlled multicentre study of the influence of subcutaneous recombinant human erythropoietin on anaemia and transfusion dependency in patients with ovarian carcinoma treated with platinum-based chemotherapy. Med Oncol. 1998;15(3):174-182.

28. Oberhoff C, Neri B, Amadori D, et al. Recombinant human erythropoietin in the treatment of chemotherapy-induced anemia and prevention of transfusion requirement associated with solid tumors: a randomized, controlled study. Ann Oncol. 1998;9(3):255-260.

29. Kunikane H, Watanabe K, Fukuoka M, et al. Double-blind randomized control trial of the effect of recombinant human erythropoietin on chemotherapy-induced anemia in patients with non-small cell lung cancer. Int J Clin Oncol. 2001;6(6):296-301.

30. Osterborg A, Brandberg Y, Molostova V, et al. Randomized, double-blind, placebo-controlled trial of recombinant human erythropoietin, epoetin Beta, in hematologic malignancies. J Clin Oncol. 2002;20(10):2486-2494.

31. Henke M, Laszig R, Rube C, et al. Erythropoietin to treat head and neck cancer patients with anaemia undergoing radiotherapy: randomised, double-blind, placebo-controlled trial. Lancet. 2003;362(9392):1255-1260.

32. Glossmann JP, Engert A, Wassmer G, et al. Recombinant human erythropoietin, epoetin beta, in patients with relapsed lymphoma treated with aggressive sequential salvage chemotherapy--results of a randomized trial. Ann Hematol. 2003;82(8):469-475.

33. Boogaerts M, Coiffier B, Kainz C. Impact of epoetin beta on quality of life in patients with malignant disease. Br J Cancer. 2003;88(7):988-995.

34. Aapro M, Leonard RC, Barnadas A, et al. Effect of once-weekly epoetin beta on survival in patients with metastatic breast cancer receiving anthracycline- and/or taxane-based chemotherapy: results of the Breast Cancer-Anemia and the Value of Erythropoietin (BRAVE) study. J Clin Oncol. 2008;26(4):592-598.

35. Bohlius J, Langensiepen S, Schwarzer G, et al. Erythropoietin for patients with malignant disease. Cochrane Database Syst Rev. 2004(3): CD003407.

36. Seidenfeld J, Piper M, Bohlius J, et al. Comparative Effectiveness of Epoetin and Darbepoetin for Managing Anemia in Patients Undergoing Cancer Treatment: Agency for Healthcare Research and Quality; 2006.

37. Bohlius J, Wilson J, Seidenfeld J, et al. Recombinant human erythropoietins and cancer patients: updated meta-analysis of 57 studies including 9353 patients. $J$ Natl Cancer Inst. 2006;98(10):708-714.

38. Wilson J, Yao GL, Raftery J, et al. A systematic review and economic evaluation of epoetin alpha, epoetin beta and darbepoetin alpha in anaemia associated with cancer, especially that attributable to cancer treatment. Health Technol Assess. 2007;11(13): 1-202, iii-iv.

39. Boogaerts M, Oberhoff C, Ten Bokkel Huinink W, Nowrousian MR, Hayward CR, Burger HU. Epoetin beta (NeoRecormon) therapy in patients with solid tumours receiving platinum and non-platinum chemotherapy: a meta-analysis. Anticancer Res. 2006;26(1B):479-484.
40. Glaspy J, Bukowski R, Steinberg D, Taylor C, Tchekmedyian S, Vadhan-Raj S. Impact of therapy with epoetin alfa on clinical outcomes in patients with nonmyeloid malignancies during cancer chemotherapy in community oncology practice. Procrit Study Group. J Clin Oncol. 1997;15(3):1218-1234.

41. Demetri GD, Kris M, Wade J, Degos L, Cella D. Quality-of-life benefit in chemotherapy patients treated with epoetin alfa is independent of disease response or tumor type: results from a prospective community oncology study. Procrit Study Group. J Clin Oncol. 1998;16(10): $3412-3425$

42. Littlewood TJ, Bajetta E, Nortier JW, Vercammen E, Rapoport B. Effects of epoetin alfa on hematologic parameters and quality of life in cancer patients receiving nonplatinum chemotherapy: results of a randomized, double-blind, placebo-controlled trial. J Clin Oncol. 2001;19(11):2865-2874.

43. Bottomley A, Thomas R, van Steen K, Flechtner H, Djulbegovic B. Human recombinant erythropoietin and quality of life: a wonder drug or something to wonder about? Lancet Oncol. 2002;3(3):145-153.

44. Erythropoietin analogues: an unnecessary class of drugs. Lancet Oncol. 2008;9(2):81.

45. Steensma DP. A premature obituary for erythropoietin analogues. Lancet Oncol. 2008;9(4):316.

46. Bennett CL, Silver SM, Djulbegovic B, et al. Venous thromboembolism and mortality associated with recombinant erythropoietin and darbepoetin administration for the treatment of cancer-associated anemia. JAMA. 2008;299(8):914-924.

47. Aapro M, Scherhag A, Burger HU. Effect of treatment with epoetin-beta on survival, tumour progression and thromboembolic events in patients with cancer: an updated meta-analysis of 12 randomised controlled studies including 2301 patients. Br J Cancer. 2008;99(1):14-22.

48. Besarab A, Bolton WK, Browne JK, et al. The effects of normal as compared with low hematocrit values in patients with cardiac disease who are receiving hemodialysis and epoetin. $N$ Engl $J$ Med. 1998;339(9):584-590.

49. Singh AK, Szczech L, Tang KL, et al. Correction of anemia with epoetin alfa in chronic kidney disease. $N$ Engl J Med. 2006;355(20):2085-2098.

50. An open-label, randomized, parallel-group study to confirm the safety and efficacy of procrit ${ }^{\circledR}$ (Epoetin Alfa) administered perioperatively vs the standard of care in blood conservation in subjects undergoing major elective spinal surgery. Available at: http://download.veritasmedicine. com/PDF/CR004621_ToplineResults.pdf. Accessed Aug 25, 2008.

51. Glaspy J, Österborg A, Ludwig H, et al. Evaluation of the association between hemoglobin $(\mathrm{Hb})$ events and safety outcomes in cancer patients (pts) with chemotherapy-induced anemia (CIA): an integrated analysis of patient-level data from 6 randomized, placebo-controlled trials (RCTs) of darbepoetin alfa (DA). Eur J Cancer (Suppl). 2007;5(4):147-148.

52. Dicato M. Venous thromboembolic events and erythropoiesis-stimulating agents: an update. Oncologist. 2008;13 Supp1 3:11-15.

53. Leyland-Jones B. Breast cancer trial with erythropoietin terminated unexpectedly. Lancet Oncol. 2003;4(8):459-460.

54. Kaanders JH, van der Kogel AJ. Erythropoietin to treat anaemia in patients with head and neck cancer. Lancet. 2004;363(9402): 78-79; author reply 81-72.

55. Leyland-Jones B, Mahmud S. Erythropoietin to treat anaemia in patients with head and neck cancer. Lancet. 2004;363(9402):80; author reply $81-82$.

56. Haddad R, Posner M. Erythropoietin to treat anaemia in patients with head and neck cancer. Lancet. 2004;363(9402):79-80; author reply 81-72.

57. US Food and Drug Administration. Oncologic Drugs Advisory Commitee. March 13th, 2008. Briefing Information. Available at: http://www. fda.gov/ohrms/dockets/ac/08/briefing/2008-4345b2-01-FDA.pdf. Accessed Sept 20th, 2008.

58. Hedenus M, Adriansson M, San Miguel J, et al. Efficacy and safety of darbepoetin alfa in anaemic patients with lymphoproliferative malignancies: a randomized, double-blind, placebo-controlled study. $\mathrm{Br} J$ Haematol. 2003;122(3):394-403. 
59. US Food and Drug Administration. Oncologic Drugs Advisory Commitee. May 10th, 2007. Briefing Information. Available at: www. fda.gov/OHRMS/DOCKETS/AC/07/briefing/2007-4301b2-02-FDA. pdf Accessed Sept 20th, 2008.

60. Thomas G, Ali S, Hoebers FJP, et al. Phase III trial to evaluate the efficacy of maintaining hemoglobin levels above $12.0 \mathrm{~g} / \mathrm{dL}$ with erythropoietin vs above $10.0 \mathrm{~g} / \mathrm{dL}$ without erythropoietin in anemic patients receiving concurrent radiation and cisplatin for cervical cancer. Gynecologic Oncology. 2008;108(2):317-325.

61. Overgaard J, Hoff C, Hansen HS, et al. Randomized study of the importance of Novel Erythropoiesis Stimulating Protein (Aranesp (R)) for the effect of radiotherapy in patients with primary squamous cell carcinoma of the head and neck (HNSCC) - the Danish Head and Neck Cancer Group DAHANCA 10 randomized trial. Ejc Supplements. 2007;5(6):7-7.

62. Wright JR, Ung YC, Julian JA, et al. Randomized, double-blind, placebo-controlled trial of erythropoietin in non-small-cell lung cancer with disease-related anemia. J Clin Oncol. 2007;25(9):1027-1032.

63. Smith RE, Aapro MS, Ludwig H, et al. Darbepoetin alfa for the treatment of anemia in patients with active cancer not receiving chemotherapy or radiotherapy: Results of a phase III, multicenter, randomized, double-blind, placebo-controlled study. Journal of Clinical Oncology. 2008;26(7):1040-1050.

64. Osterborg A, Brandberg Y, Hedenus M. Impact of epoetin-beta on survival of patients with lymphoproliferative malignancies: long-term follow up of a large randomized study. $\mathrm{Br} J$ Haematol. 2005;129(2):206-209.

65. Arcasoy MO. Erythropoiesis-stimulating agent use in cancer: preclinical and clinical perspectives. Clin Cancer Res. 2008;14(15):4685-4690.

66. Henke M, Mattern D, Pepe M, et al. Do erythropoietin receptors on cancer cells explain unexpected clinical findings? J Clin Oncol. 2006;24(29):4708-4713.

67. Agarwal N, Gordeuk VR, Prchal JT. Are erythropoietin receptors expressed in tumors? Facts and fiction - more careful studies are needed. J Clin Oncol. 2007;25(13):1813-1814; author reply 1815.

68. Della Ragione F, Cucciolla V, Borriello A, Oliva A, Perrotta S. Erythropoietin receptors on cancer cells: a still open question. J Clin Oncol. 2007;25(13):1812-1813; author reply 1815.

69. Fandrey J. Erythropoietin receptors on tumor cells: what do they mean? Oncologist. 2008;13 Suppl 3:16-20.

70. Jelkmann W, Laugsch M. Problems in identifying functional erythropoietin receptors in cancer tissue. J Clin Oncol. 2007;25(12):1627-1628; author reply 1628 .
71. Hardee ME, Cao Y, Fu P, et al. Erythropoietin blockade inhibits the induction of tumor angiogenesis and progression. PLOS ONE. 2007; 2:e549.

72. Okazaki T, Ebihara S, Asada M, Yamanda S, Niu K, Arai H. Erythropoietin promotes the growth of tumors lacking its receptor and decreases survival of tumor-bearing mice by enhancing angiogenesis. Neoplasia. 2008;10(9):932-939.

73. McKoy JM, Stonecash RE, Cournoyer D, et al. Epoetin-associated pure red cell aplasia: past, present, and future considerations. Transfusion. 2008;48(8):1754-1762.

74. US Food and Drug Administration. Follow Up to the January 3, 2008 Communication about an ongoing safety review erythropoiesis-stimulating agents (ESAs) epoetin alfa (marketed as Procrit, Epogen) darbepoetin alfa (marketed as Aranesp). Available at: http://www.fda.gov/cder/drug/infopage/RHE/default.htm. Accessed Aug 25, 2008.

75. European Medicines Evaluation Agency. EMEA recommends a new warning for epoetins for their use in cancer patients. Available at: http://www.emea.europa.eu/pdfs/human/press/pr/33396308en.pdf. Accessed Aug 25, 2008.

76. European Medicines Evaluation Agency. Epoetins and the risk of tumour growth progression and thromboembolic events in cancer patients and cardiovascular risks in patients with chronic kidney disease. Available at: http://www.emea.europa.eu/pdfs/human/press/ pus/49618807en.pdf. Accessed Aug 25, 2008.

77. Bokemeyer C, Aapro MS, Courdi A, et al. EORTC guidelines for the use of erythropoietic proteins in anaemic patients with cancer: 2006 update. Eur J Cancer. Jan 2007;43(2):258-270.

78. National Comprehensive Cancer Network. Cancer- and Chemotherapy-Induced Anemia v2.2009. Available at: http://www.nccn.org/ professionals/physician_gls/PDF/anemia.pdf. Accessed Sep 18th, 2008.

79. National Institute for Health and Clinical Excellence. Epoetin alfa, epoetin beta and darbepoetin alfa for cancer treatment-induced anaemia. Available at: http://www.nice.org.uk/Guidance/TA142. Accessed Sept 20th, 2008.

80. Pirker R, Ramlau RA, Schuette W, et al. Safety and efficacy of darbepoetin alpha in previously untreated extensive-stage small-cell lung cancer treated with platinum plus etoposide. J Clin Oncol. 2008;26(14):2342-2349.

81. Grote T, Yeilding AL, Castillo R, et al. Efficacy and safety analysis of epoetin alfa in patients with small-cell lung cancer: a randomized, double-blind, placebo-controlled trial. J Clin Oncol. 2005;23(36): 9377-9386. 